\title{
Identification of three regions essential for interaction between a $\sigma$-like factor and core RNA polymerase
}

\author{
Paul F. Cliften, ${ }^{1}$ Jae-Young Park, ${ }^{2}$ Brian P. Davis, ${ }^{1}$ Sei-Heon Jang ${ }^{2}$ and Judith A. Jaehning, ${ }^{1,3}$ \\ ${ }^{1}$ Department of Biochemistry and Molecular Genetics and Program in Molecular Biology, University of Colorado Health \\ Sciences Center, Denver, Colorado 80262 USA; ${ }^{2}$ Department of M olecular Biology, Taegu University, Taegu, Korea
}

\begin{abstract}
The cyclic interactions that occur between the subunits of the yeast mitochondrial RNA polymerase can serve as a simple model for the more complex enzymes in prokaryotes and the eukaryotic nucleus. We have used two-hybrid and fusion protein constructs to analyze the requirements for interaction between the single subunit core polymerase (Rpo4lp), and the $\sigma$-like promoter specificity factor (Mtflp). We were unable to define any protein truncations that retained the ability to interact, indicating that multiple regions encompassing the entire length of the proteins are involved in interactions. We found that 9 of 15 nonfunctional (petite) point mutations in Mtflp isolated in a plasmid shuffle strategy had lost the ability to interact. Some of the noninteracting mutations are temperature-sensitive petite (ts petite); this phenotype correlates with a precipitous drop in mitochondrial transcript abundance when cells are shifted to the nonpermissive temperature. One temperature-sensitive mutant demonstrated a striking pH dependence for core binding in vitro, consistent with the physical properties of the amino acid substitution. The noninteracting mutations fall into three widdy spaced clusters of amino acids. Two of the clusters are in regions with amino acid sequence similarity to conserved regions 2 and 3 of $\sigma$ factors and related proteins; these regions have been implicated in core binding by both prokaryotic and eukaryotic $\sigma$-like factors. By modeling the location of the mutations using the partial structure of Escherichia coli $\sigma^{70}$, we find that two of the clusters are potentially juxtaposed in the three-dimensional structure. Our results demonstrate that interactions between $\sigma$-like specificity factors and core RNA polymerases require multiple regions from both components of the holoenzymes.
\end{abstract}

[Key Words: RNA polymerase; $\sigma$ factor; transcription initiation; mitochondrial transcription; MTF1; RPO 41; two-hybrid]

Received June 17, 1997; revised version accepted August 26, 1997.

The complex RNA polymerases of eukaryotes and prokaryotes require auxiliary factors specific for the initiation phase of transcription. These factors associate with the core polymerases to form holoenzymes competent for promoter recognition, selective DNA binding, and opening of the doublestranded DNA at the start site of transcription. Shortly after initiation, the factors are released as the RN A polymerase makes the transition into its el ongating form. The factors associated with eukaryotic nuclear RN A polymerase II (Pol II) before initiation, and released shortly after transcription is initiated include TFIIB, TFIID, TFIIE, TFIIF, and TFIIH (Conaway and Conaway 1993; Zawel and Reinberg 1995). In bacterial cells, members of the family of $\sigma$ factors carry out most of the functions of the many eukaryotic nuclear factors (for review, see Helmann 1994). The interaction of a $\sigma$ factor with the core polymerase al ters the confor-

${ }^{3}$ Corresponding author.

E-MAIL jaehningj@defiance UCHSC.edu; FAX (303) 315-3326. mation of both the polymerase and the $\sigma$ factor to expose amino acids critical for promoter recognition, and to allow the loading of the polymerase onto the DN A (Dombroski et al. 1993; Polyakov et al. 1995). Although much has been learned about how $\sigma$ factors and other sequence-specific binding factors interact with DN A, relatively little is known about the interactions of these factors with the subunits of core polymerases and how these interactions influence conformational changes in both components of the holoenzyme. In this work, we have used the yeast mitochondrial RNA polymerase (mt RNAP) as a simple model to examine the interaction between a promoter specificity factor and a core polymerase.

The core mt RN AP is a single polypeptide encoded by the nuclear gene RPO 41. Rpo41p shares nine regions of amino acid sequence similarity with the single subunit RN A polymerases of the T 7 and T 3 bacteriophage (M asters et al. 1987; Jang and Jaehning 1994). These regi ons include the amino acids known to be required for struc- 
ture and function of the catalytic domain of the phage polymerases (Delarue et al. 1990; Sousa et al. 1993). However, unlike the phage polymerases that function independently, Rpo4lp requires a specificity factor encoded by the nuclear MTFl gene. M tflp has only limited amino acid similarity to $\sigma$ factors (Jang and Jaehning 1991), but functions in many ways like $\sigma$ in that it is required for promoter recognition and initiation of transcription. Although Mtflp does not bind to its simple nine-base promoter (consensus ATATAAGTA; Osinga et al. 1982) on its own, it interacts with the core polymerase in solution to create a holoenzyme capable of promoter recognition ( $M$ angus et al. 1994). Mtflp is released after a short transcript has been synthesized and is available for interaction with a new core subunit, also reminiscent of $\sigma$ factors ( $M$ angus et al. 1994). The mitochondrial RNA polymerase therefore undergoes the same cycle of interactions as do the more complicated prokaryotic and eukaryotic nuclear enzymes, but requires only two polypeptides rather than the four to more than 30 used in the more complex systems.

In this work we have investigated the requirements for interaction between Mtf1p and Rpo41p. A comprehensive del etion analysis of both proteins failed to identify a simple interaction region, indicating that several regions of both proteins may be involved in the protein-protein interactions. We have demonstrated that this is the case for $\mathrm{M} t \mathrm{t} 1 \mathrm{p}$ by identifying three regions required for interactions with Rpo4lp. Two of these regions are similar to regions of $\sigma$-like factors shown to have a role in interactions with the prokaryotic and eukaryotic core polymerases. This analysis establishes the yeast mt RNAP as a useful model for the analysis of protein-protein interactions during the transcription cycle, and demonstrates that core polymerase/accessory factor interactions involve complex-binding surfaces on both components of the holoenzyme.

\section{Results}

The interaction between Mtf1p and Rpo4lp can be detected in two-hybrid constructs

The analysis of interactions between $\sigma$-like factors and core polymerases is complicated because of the number of polypeptides in most core RN A polymerases. With the two-component mitochondrial RNA polymerase it is possible to use the powerful technique of two-hybrid analysis (Bartel et al. 1993; Phizicky and Fields 1995) to determine regions and/or specific amino acids of the R po4lp core and the M tf1p $\sigma$-like specificity factor necessary for protein-protein interactions. Although twohybrid analyses of proteins that normally interact in the cytoplasm have been successful in the nuclear environment required for the technique, it was critical that we establish that the relatively weak interactions between the mtRN AP subunits (Mangus et al . 1994) could be detected in two-hybrid constructs. Initially, full-length polymerase subunits were tested for interaction in this assay. Mtflp was fused to the LexA DNA-binding do- main, whereas Rpo41p was fused to the Vp16 transcripti onal activator in vectors described by Hollenberg et al. (1995; Materials and M ethods). $\beta$-Galactosidase activity was undetectable with the fusion constructs on their own (except for a weak positive signal with the LexA:M tf1p construct), or in combination with the unfused vector constructs. High levels of $\beta$-gal actosidase were only observed when the LexA:M tflp construct was present with the VP16:Rpo41p construct (see below).

\section{Deletions of Rpo41p and Mtf1p fail to identify a discrete interaction region}

Two-hybrid analyses have been used to delineate small regions of proteins necessary and sufficient for proteinprotein interactions (Bartel et al. 1993; Phizicky and Fields 1995). Therefore, we asked if del etion constructs could be used to define the region of interaction between the two proteins. As shown in Figure 1, several deletion constructs were made for both Mtflp (Fig. 1A) and Rpo41p (Fig. 1B) in two-hybrid vector backbones. The six Mtflp deletions included three carboxy-terminal deletions, one amino-terminal deletion, and two internal deletions. The two internal del etions removed amino acids conserved with $\sigma$ regions 2.1 and 2.2. All constructs were expressed in yeast cells and produced proteins of the predicted sizes (Fig. 2A; data not shown). Furthermore, the deletion constructs were expressed at levels that were equival ent to the full-length product (Fig. 2A). However, none of the M tflp deletion constructs showed any interaction, as measured by $\beta$-galactosidase activity, with the core polymerase in this assay (data not shown). These results suggest that it is not a single domain but multiple regions of the folded structure of $M t f 1 p$ whose contact with Rpo4lp is required to produce a stable interaction.

A similar analysis was conducted with Rpo4lp. R po41p is larger than its phage relatives and contains an amino-terminal extension of $\sim 300$ amino acids that has no similarity to the phage polymerases (Masters et al. 1987). Because the phage polymerases do not require a specificity factor, we have speculated that the aminoterminal extension may have a role in the interaction with the specificity factor (Jaehning 1993). To determine if this sequence alone is capable of interacting with Mtflp, we fused the amino-terminal sequence (amino acids 1-311) of Rpo41p to the Vp16 activation region. The amino-terminal fragment showed no interaction with Mtflp by this analysis (data not shown). However, this fusion construct was not detected in vivo by Western bl ot analysis. Four additional R po41p constructs (Fig. 1B) were tested for interaction with Mtf1p. Each of the constructs accumulated in yeast cells (Fig. 2B), but none was capable of interaction with M tflp (data not shown). Two constructs (Rpo41p1-597 and Rpo41p1-918) contain the amino-terminal extension, but are unable to mediate interaction with Mtflp. The carboxy-terminal polymerase region, Rpo41p311-1351, is also incapable of interacting with Mtflp. Mtflp may therefore interact with amino acids in both the amino-terminal extension and the polymerase domain. 


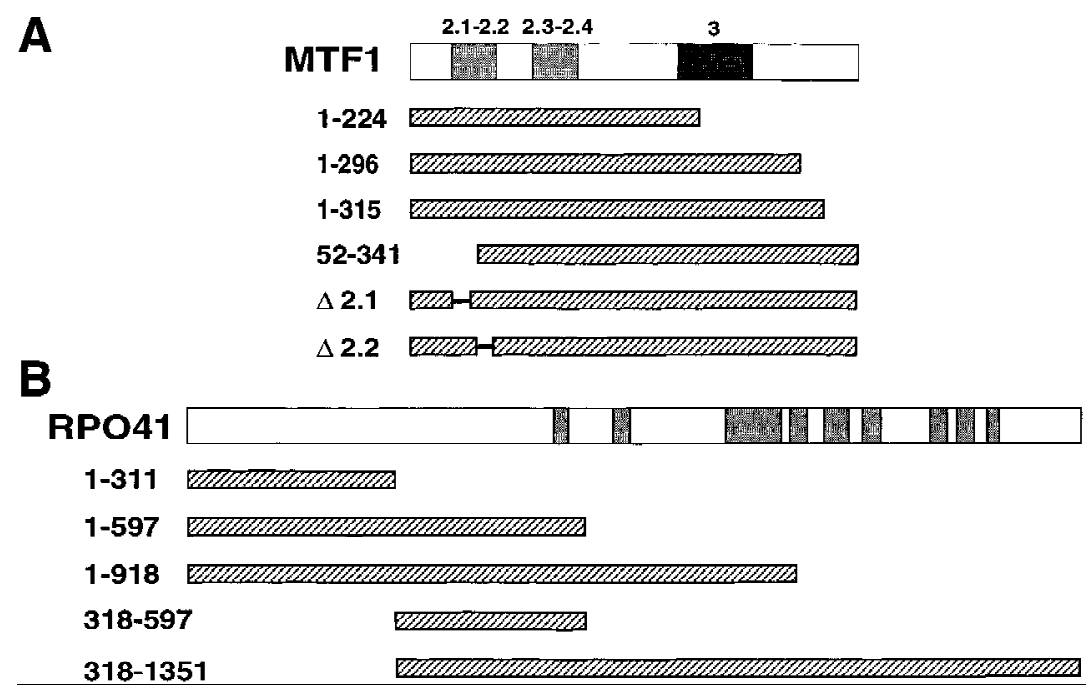

Figure 1. Two-hybrid del etion constructs. (A) $M$ tflp deletions were fused to the LexA DNAbinding region and tested for interaction with a full-length Rpo4lp two-hybrid construct . (B) Rpo4lp del etions were fused to the $\mathrm{Vp16}$ activator region and tested for interaction with a full-length LexA:M tf1p construct. Strains, vectors, and protocols are described in Materials and $M$ ethods. N umbers refer to amino acid positions retained in the constructs. Shaded boxes in the full-length maps of MTF1 and RPO 41 refer to regions conserved between $\sigma$ factors and M tf1p (Jang and Jaehning 1991) or between Rpo41p and T7 RNA polymerase (M asters et al. 1987; Jaehning 1993).
Isolation of point mutations in Mtflp that confer a petite phenotype

Because del etions in M tf1p and R po4lp failed to identify discrete regions sufficient for interaction, we turned to analysis of point mutations to identify specific residues required for the interaction. Although MTF1 is not essential for yeast cell growth, it is required for the stable replication and transmission of the mitochondrial genome (Lisowsky and M ichael is 1988). Y east strains lacking functional $M t f 1 p$ rapidly lose their full-length mitochondrial DNA, producing a petite phenotype that cannot be complemented by the subsequent expression of MTF1 (Jang and Jaehning 1991). Isolation of nonfunctional MTF1 mutations therefore requires the use of the plasmid shuffle technique where a plasmid bearing a wild-type copy of the gene is used to cover a chromosomal mutation (Sikorski and Boeke 1991). A yeast strain was created for this procedure as outlined in Figure 3.

For mutagenesis, MTF1 was amplified using low fidelity PCR conditions to create random mutations throughout the gene (M aterials and M ethods). The mutant fragments were transformed into the recipient strain and then grown on 5-fluoro-orotic acid (5FOA) to select for cells that had lost the wild-type MTF1 plasmid with the URA 3 marker. The mtf1 mutants were tested subsequently for mitochondrial function by growth on a nonfermentable carbon source. Strains that were unable to grow on glycerol plates (petite), or unable to grow on glycerol plates at $37^{\circ} \mathrm{C}$ temperature-sensitive petite (ts petite) were collected for further analysis.

From 10,000 primary transformants, 22 petite and ts petite mutants were identified and sequenced to determine the mutation responsible for the petite phenotype. Six of the mutants contained nonsense codons, whereas the other 17 mutants contained either single (6), double (9), or triple (2) missense mutations (Table 1). Missense mutations were identified between codons 40 and 247. To increase the pool of single missense mutations, we reconstructed many of the mutations as single point mutations using site-directed mutagenesis. Oligonucleotides based on the sequenced mutations were designed for mutagenesis of the wild-type sequence ( $M$ aterial $s$ and Methods). The isolated single mutations were retested using the plasmid shuffle to determine the effect of the single mutations in vivo. $\mathrm{N}$ ine of the 10 reconstructed mutations were either petite or ts petite when present as single mutations (Table 1). Although not all of the identified mutations were reconstructed, we did isolate a substantial pool of defective Mtflp mutations. In total, 15 petite or ts petite point mutations were identified.

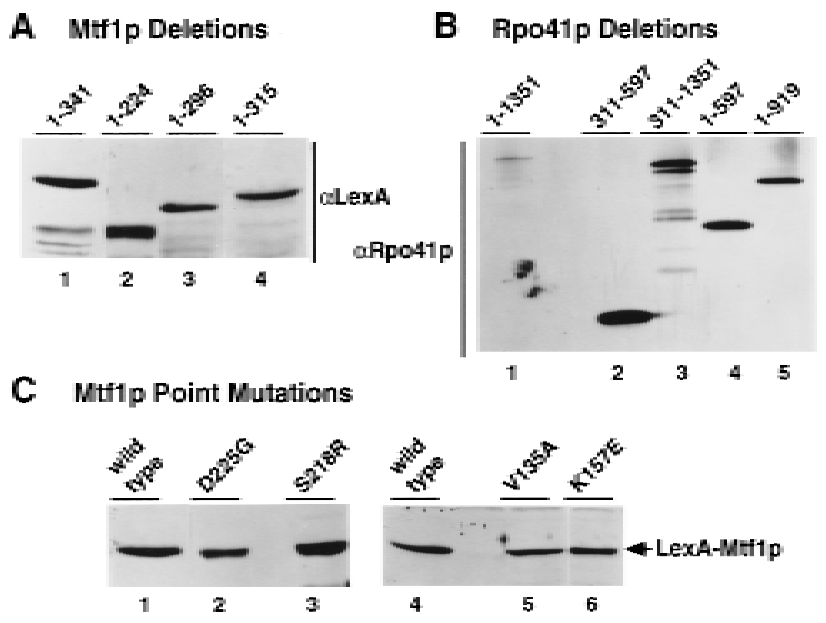

Figure 2. Confirmation of the expression of the two-hybrid constructs. Two-hybrid fusion proteins were detected in extracts of whole-cell yeast grown at $30^{\circ} \mathrm{C}$. Rpo4lp fusion proteins were visualized using an anti-Rpo4lp antibody, whereas M tf1p fusion proteins were detected with an anti-LexA antibody ( $\mathrm{Ma}$ terials and M ethods). Equal amounts of yeast cell extracts were analyzed for each sample. (A) M tflp carboxy-terminal del etion constructs. (B) Rpo4lp del etion constructs. (C) M tflp point mutations that are defective for interaction with Rpo4lp in the two-hybrid system. 


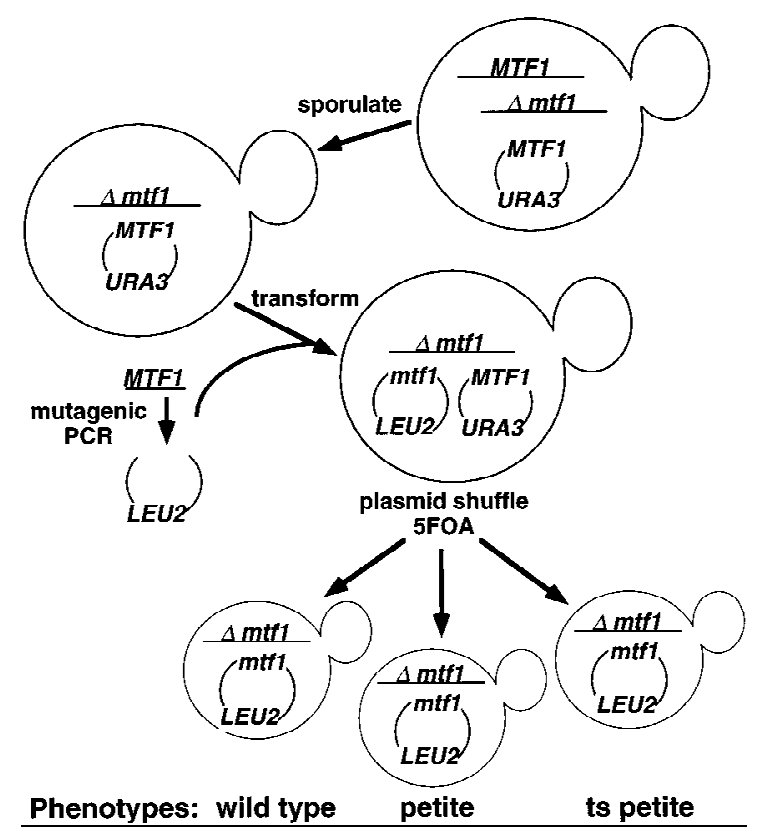

Figure 3. Plasmid shuffle isolation of PCR-generated mtf1 mutants. Plasmids, strains, and protocols are described in $\mathrm{M}$ aterials and M ethods. A haploid strain ( $\mathrm{yJH}$ H1) containing a single functional copy of MTF1 on a plasmid was transformed with plasmids bearing mutant $\mathrm{mtf} 1$ genes on a LEU 2 sel ectable plasmid. The transformants were plated onto glucose medium containing 5-FOA to sel ect for the loss of the U RA 3 plasmid bearing the wild-type copy of MTF1. The mutant al lel es were then tested for $M$ tflp function by plating the cells on a nonfermentable carbon source (YPG) . Petite and ts petite mutants were identified.

Transcription of all classes of mitochondrial genes is reduced in ts $\mathrm{mtf} 1$ mutants

It was possible that some of the defects in Mtflp function could be attributable to failure to recognize one or more of the promoters in the mitochondrial genome. We therefore analyzed patterns of mitochondrial transcription at the permissive $\left(30^{\circ} \mathrm{C}\right)$ and nonpermissive $\left(36^{\circ} \mathrm{C}\right)$ temperatures for several ts petite $\mathrm{mtf} 1$ mutant strains (Fig. 4; data not shown). Strains of yeast bearing the wildtype or temperature-sensitive (L53H and I154T) allel es of MTF1 were grown in minimal glucose media at the permissive temperature and then shifted to the nonpermissive temperature. Samples of yeast were collected at intervals and total RNA was isolated, fractionated, and hybridized with oligonucleotide probes specific for mitochondrial 14S rRNA, mRNAs for the COB and O LI 1 genes, and the tRN As for Glu, Ser1, Trp, Thr (ACN ), $_{\text {, }}$ $\mathrm{f}-\mathrm{M}$ et, and Phe, as well as the cytoplasmic 18S rRNA as a normal ization control. These genes represent 7 of the 12 known mitochondrial transcription units and include several of the different promoter sequence variations (Dieckmann and Staples 1994). Some of the hybridization analyses are shown in Figure 4A and the quantitation of these data are presented in Figure 4B.

Three conclusions can be drawn from the results in Figure 4. First, mitochondrial gene expression is reduced significantly in the ts mutants relative to wild-type expression, even at the permissive temperature (Fig. 4A). Because the strains bearing the mutant al leles of $\mathrm{Mtflp}$ grow almost as well as wild type on glycerol medium, mitochondrial function can be maintained apparently with only $10 \%-20 \%$ of the wild-type level of mitochondrial transcripts. Second, there is a rapid decrease in mitochondrial RNA abundance in both the wild-type and mutant strains after the shift to the nonpermissive temperature, but the mutants do not recover and RN A levels decrease to almost undetectable levels (Fig. 4B).

Finally, the abundance of all mitochondrial transcripts that we analyzed was reduced to a similar extent (Fig. $4 A, B$; data not shown). These mtf1 mutations therefore affect the transcription of all mitochondrial genes and are not specifically defective for recognition of a subset of mitochondrial promoters. Under the conditions used in these assays, petites do not start to accumulate in the mutant strains until about $24 \mathrm{hr}$ after the shift to the nonpermissive temperature (data not shown). During this period the mutants maintained levels of mitochondrial DNA similar to those found in the wild-type strain (data not shown). Therefore, the petite phenotype caused by the mtf1 mutations is caused by a defect in transcription of mitochondrial genes, not by a rapid loss of mitochondrial DN A. This defect could be caused by failure to interact with the core polymerase, inability to recognize or bind to the mitochondrial promoter, or loss-of-function in other steps in initiation. In the following sections we have tested these mutations for the first of these possible defects.

Some of the mtf1 mutations no longer interact with Rpo41p in the two-hybrid assay

We introduced each of the point mutations into the twohybrid LexA fusi on vector (M aterials and M ethods). Unlike the deletion mutations described above, most (10 of 15) of the mutants retained the ability to interact with Rpo41p, as determined by qualitative production of $\beta$ gal actosidase in filter assays (data not shown). However, five of the 15 mutations (L53H, V135A, I154T, S218R, and D225G; see Fig. 5) were negative for $\beta$-gal actosi dase production, indicating that they had lost the ability to interact with Rpo41p. The inability of these mutants to interact was not attributable to lowered or abolished expression of the fusion constructs, as all of the noninteracting mutants are expressed at levels equival ent to wild-type (Fig. 2C). Because many of the petite MTF1 mutants were isolated as temperature-sensitive mutations, we repeated the filter assays after growing cells at $37^{\circ} \mathrm{C}$ (data not shown). Two additional mutations (Y 42C and K157E) fail to interact at the nonpermissive temperature.

When the qualitative assays were followed by quantitative measurement of $\beta$-galactosidase activity, we found that many of the petite mutations associate with Rpo4lp at levels that are indistinguishable from the wild-type protein (Fig. 5). However, consistent with the filter assays the noninteracting mutants L53H, V135A, 
Table 1. Petite and ts petite mutations identified by PCR mutagenesis of MTF1

\begin{tabular}{llll}
\hline Mutations & Phenotype & M utations & Phenotype \\
\hline N onsense & & single amino acid & Y42C \\
K35Stop & petite & L53H & ts petite \\
Q60Stop & petite & I154T & ts petite \\
K71Stop & petite & K157E & ts petite \\
R189Stop & petite & S218R & ts petite \\
K203Stop & petite & I221K & ts petite \\
& & singleamino acid & petite \\
Multiple amino acid & & isolated from multiple & \\
H44P/V135A & petite & H44P & Y54F \\
Y54F/E114V & petite & R79H & ts petite \\
R79H/M247T & petite & S81N & petite \\
I59V/K71E/S81N & petite & E114V & wild type \\
C192F/E233D & ts petite & V135A & petite \\
Q219R/D225G & petite & C192F & ts petite \\
S190P/L228S & petite & Q219R & ts petite \\
K40R/Q60R & ts petite & D225G & ts petite \\
K67E/Y108N & ts petite & petite \\
Y68H/D104G/T 134S & ts petite & petite \\
L82P/E141V & ts petite & L228S & \\
\hline
\end{tabular}

Twenty-two petite or ts petite mtf1 mutants were identified by a plasmid shuffle technique (Materials and Methods). Mutants containing nonsense, missense, and multiple missense mutations were identified. Many of the multiple missense mutations were isolated so that single mutations (shown in bold) could be analyzed separately.

I154T, S218R, and D225G produce no $\beta$-galactosidase activity above background levels. We al so identified two mutants that have intermediate levels of interaction. Mutant $1221 \mathrm{~K}$ generates $<50 \%$ and mutant $\mathrm{H} 44 \mathrm{P}$ produces $<25 \%$ of the $\beta$-galactosidase activity of the wild- type construct. The two temperature-sensitive mutations Y $42 C$ and K157E produce $\beta$-galactosidase at levels that are equivalent to the wild-type protein at their permissive temperatures $\left(30^{\circ} \mathrm{C}\right.$ and $23^{\circ} \mathrm{C}$, respectively), but are reduced severely in interaction at their nonpermis-
A

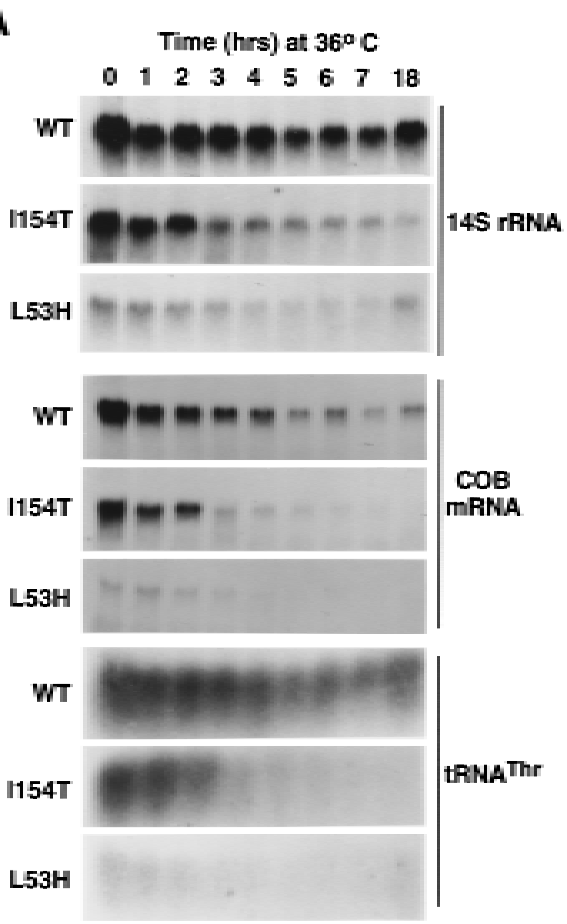

$\begin{array}{lllllllll}1 & 2 & 3 & 4 & 5 & 6 & 7 & 8 & 9\end{array}$

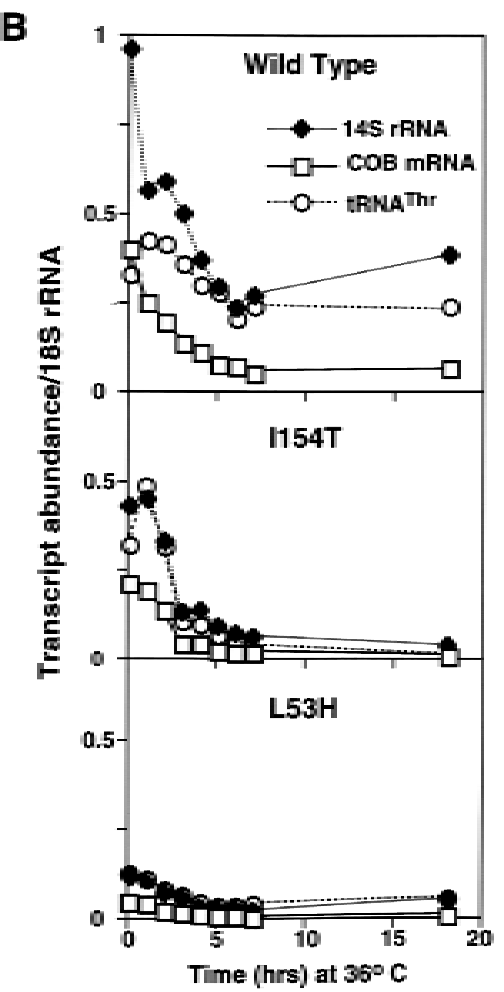

Figure 4. Ts mtf1 mutants are defective in all classes of mitochondrial gene transcription. Wild-type (wt) and ts petite strains bearing $\mathrm{mtf1}$ mutations $\mathrm{L} 53 \mathrm{H}$ and I154T were grown in minimal glucose medium at $30^{\circ} \mathrm{C}$ and shifted to $37^{\circ} \mathrm{C}$. Total RNA was harvested from cells immediately before and at the indicated time intervals after the shift to the nonpermissive temperature. (A) Blots of the isolated RNAs were hybridized with labeled 14S rRNA, COB, or tRN A THR(ACN) oligonucleotide probes to analyze the abundance of mitochondrial transcripts. (B) Hybridization to the blots was quantitated by Phosphorlmager analysis to directly compare levels of transcripts. The blots were hybridized to an 18S rRN A oligonucleotide probe to normalize for loading and transfer. Strains, plasmids, and protocols are described in Materials and Methods. 
Figure 5. Identification of point mutations in Mtflp that fail to interact with Rpo4lp. $\beta$-Galactosidase activity is shown for the LexA:Mtf1p construct alone and the LexA:M tf1p construct with the VP16:Rpo41p construct. Interaction between the M tflp mutants and Rpo4lp was determined for cells grown at $30^{\circ} \mathrm{C}$ (shaded bar). Activity for ts mutants $Y 42 C$ and K157E is al so shown for cells grown at $37^{\circ} \mathrm{C}$ (hatched bar) or $23^{\circ} \mathrm{C}$ (crosshatched bar), respectively, to demonstrate the temperature-sensitive nature of the interaction. $\beta$-Galactosidase activity is expressed in Miller units (Miller 1972).

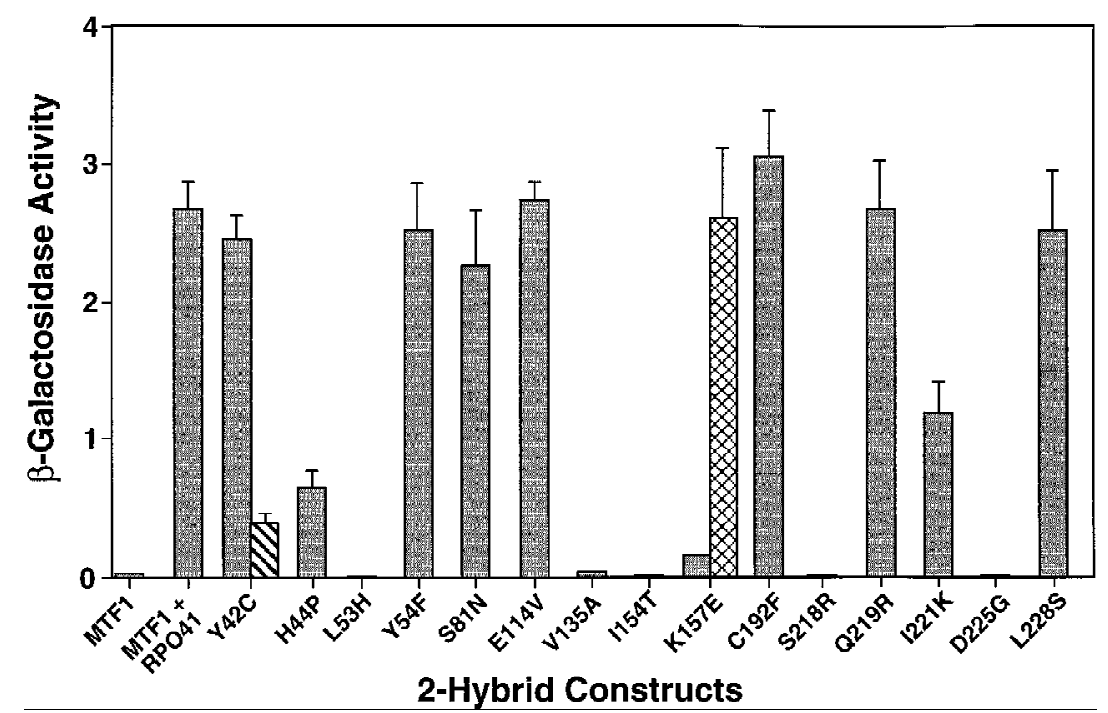

sive temperatures $\left(36^{\circ} \mathrm{C}\right.$ and $30^{\circ} \mathrm{C}$, respectively). In all, nine mtf1 mutations are fully, partially, or conditionally defective for interaction with the core polymerase.

Confirmation of the two-hybrid analyses with biochemical association assays

To confirm the two-hybrid data we used a biochemical affinity assay (Mangus et al. 1994) to demonstrate that Rpo4lp and Mtflp interact in solution in the absence of DNA. For this assay the mtf1 mutants were fused to glutathione S-transferase (GST) and mutant and wildtype $\mathrm{Mtflp-GST}$ fusions were bound to a glutathione agarose column ( $\mathrm{M}$ aterials and Methods). A whole-cell yeast extract containing Rpo41p was loaded onto the fusion protein columns that were washed subsequently and step-eluted to rel ease any Rpo41p that had bound to the M tf1p fusions on the columns (M aterials and M ethods). R po4lp that was bound to and eluted from the columns was detected by an anti-Rpo4lp antibody ( $M$ angus et al. 1994).

As shown in Figure 6, the column chromatography results confirm the two-hybrid observations. As controls, the wild-type fusion and two interacting mutants, S81N and E114V (Fig. 6; data not shown) were tested for interaction. Rpo4lp bound efficiently to all three fusion constructs. Consistent with the two-hybrid results, Rpo4lp showed little ability to bind to the noninteracting mutants V135A and S218R (Fig. 6). N oninteracting mutants L53H, I154T, and D225G al so show no Rpo41p binding in this assay (data not shown). Mutants H44P (Fig. 6) and $1221 \mathrm{~K}$ (data not shown) show intermediate levels of interaction with Rpo41p in this assay, consistent with the intermediate interaction observed in the two-hybrid assay (note $\beta$-gal actosidase units in parentheses in Fig. 6). Additionally, mutant K157E, which is temperature-sensitive for interaction in the two-hybrid system, exhibited intermediate binding in this assay (data not shown).
In contrast to the results with the other conditional and partially defective mutants, the $Y 42 C$ fusion protein did not interact at all with Rpo4lp under the conditions of this assay (Fig. 7, top). The buffers used in all of the binding assays shown in Figure 6 contain Tris and are buffered to $\mathrm{a} \mathrm{pH}$ of 7.9 at room temperature, which is $\mathrm{pH}$ 8.3 at the $4^{\circ} \mathrm{C}$ temperature used for the binding assay. Although the $\mathrm{pH}$ of the yeast mitochondrion has not been reported, it seemed likely that the in vivo $\mathrm{pH}$ ex-

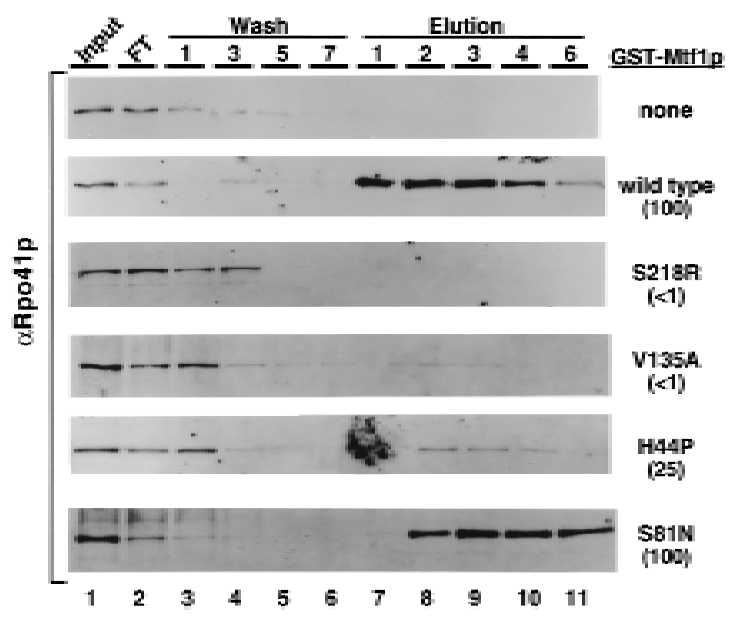

Figure 6. Biochemical confirmation of the noninteracting Mtflp mutations. GST fusion constructs of wild-type and the indicated mutant Mtflps were isolated by glutathione agarose chromatography. Whole-cell yeast extracts containing Rpo4lp were loaded onto the GST-M tf1p columns. The columns were washed to eliminate nonspecific binding, then step-eluted to release Rpo4lp bound to the column. Rpo4lp in the input, wash, and elution column fractions was detected by Western blot analysis using an anti-Rpo4lp antibody. Protocols are described in $M$ aterials and $M$ ethods. The percentage of two-hybrid interaction relative to wild-type M tf1p (from Fig. 5) is shown in parentheses for each mutant. 


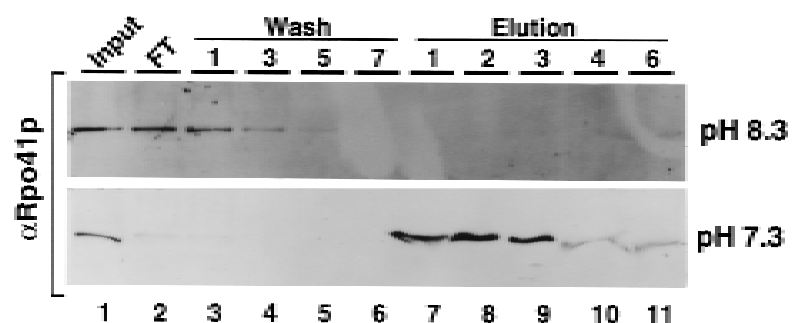

Figure 7. High pH inhibits the interaction of ts petite mutant Y 42C with Rpo4lp. The GST-M tf1p fusion construct bearing mutation $Y 42 C$ was isolated and tested for interaction with Rpo41p as outlined in the legend to Fig. 6. The columns and the whole-cell yeast extract containing Rpo4lp were equilibrated with buffers of either pH 8.3 (as shown in Fig. 6) or pH 7.3. Protocols for the detection of Rpo4lp in the eluted fractions are described in Materials and M ethods.

perienced by the $\mathrm{Y} 42 \mathrm{C}$ mutation in the nucleus for the two-hybrid assay or in the mitochondrion for the complementation assay could be significantly lower than $\mathrm{pH}$ 8.3. In addition, the change from tyrosine to cysteine alters the residue from hydrophobic to a potentially charged amino acid; the pK of cysteine is in the range of 8-9 depending on context (Walsh 1979). We therefore repeated the binding assay at $\mathrm{pH} 7.3$ to determine if partial deprotonation of the cysteine residue had reduced binding to $\mathrm{Rpo41p}$ at the higher $\mathrm{pH}$. As shown in Figure 7 (bottom), at pH 7.3 the $\mathrm{Y} 42 \mathrm{C}$ mutant interacts with Rpo4lp at levels equival ent to wild type. Furthermore, when this mutant is isol ated at the nonbinding $\mathrm{pH}$ (pH 8.3) it still retains the ability to interact with Rpo4lp when it is shifted to $\mathrm{pH} 7.3$ (data not shown). Binding of the wild type and other mutant Mtflp constructs is indistinguishable at the two different pHs (data not shown). The simplest explanation of these data is that partial negative charge on the deprotonated cysteine residue directly reduces the affinity of the mutant $M$ tflp for Rpo41p. The reversible nature of the interaction is further support of the fact that these point mutations are not unfolded or unstable proteins-they have si mpl y lost the ability to bind to Rpo4lp at levels detectable in our assays or sufficient for transcription in vivo.

\section{Discussion}

In this work, we have confirmed further the functional homology of the mitochondrial RNA polymerase specificity factor, Mtf1p, with the large family of prokaryotic and eukaryotic nuclear $\sigma$-like factors. Despite the limited amino acid sequence similarity between many of the members of this family, there are many shared functions (for review, see Helmann and Chamberlin 1988; Helmann 1994) including roles in suppression of nonspecific interactions with DNA, selective promoter sequence recognition, promoter melting, and, as described in this work, interactions with the core RNA polymerase. The mutational strategy (PCR mutagenesis and plasmid shuffle screening) used in our studies resulted in the identification of a large number of petite and ts petite mutations useful for delineating the functional regions of Mtflp. As shown in Figure 8, these mutations span much of the length of the MTF1 gene. The mutations that affect interactions with Rpo41p are shown above the linear map of the gene; the nine mutations fall in three discrete clusters that we have desi gnated A, B, and $C$. Below the map are the six petite mutations that retain the ability to interact with Rpo41p. In several cases, the two classes of mutants are closely apposed.

Additional mutations in Mtflp have been identified using a site-directed mutagenesis approach (Shadel and Clayton 1995). Although only three of the 14 mutations created in that study resulted in a petite phenotype, the position of the nonfunctional al terations confirmed that the regions of similarity with $\sigma$ factor were essential for Mtflp function. Our collection of 15 point mutations serves to establish further the importance of these conserved regions. Ten of the 15 petite mutations lie in the conserved regions identified previously (Fig. 8). The five mutations not localized to the conserved regions lie in the areas between regions 2.1/2.2 and 2.3/2.4, and between regions 2 and 3 (Fig. 8). Although we did not identify point mutations in the region carboxy-terminal to conserved region 3, there are likely to be additional essential residues in this part of the protein based on the deletion analysis reported by Shadel and Clayton (1995). They found that an additional 30 or more amino acids carboxy-terminal of region 3 were required for full function of Mtflp.

One of our point mutations (Y 42C) is in the same position identified as important by Shadel and Clayton (1995); another (L53H) is immediately adjacent to a mutation identified in that study (D52A). The fact that the adjacent ts petite mutant Y54F still interacts with the core (Fig. 5) means that we cannot predict whether the D52A mutation is defective for interaction or another step in the transcri ption reaction. This region of the pro-

\begin{tabular}{|c|c|c|c|}
\hline Cluster A & Cluster B & Cluster C & \multirow[b]{2}{*}{$\begin{array}{l}\text { Mutations Affecting } \\
\text { Rpo41p Interaction }\end{array}$} \\
\hline $\begin{array}{l}\text { L53H X } \\
\text { H44P X } \\
\text { Y } 42 \mathrm{CX}\end{array}$ & $\begin{array}{l}\text { K157E x } \\
\text { I154T x } \\
\text { V135A } x\end{array}$ & $\begin{array}{l}\text { x D225G } \\
\text { x I221K } \\
\text { x S218R }\end{array}$ & \\
\hline 2.12 .2 & 2.32 .4 & 3 & \\
\hline $\begin{array}{r}\text { Y54F x } \\
\text { S811 }\end{array}$ & $14 \mathrm{Vx}$ & & $\begin{array}{l}\text { Petite Mutations that } \\
\text { Interact with Rpo41p }\end{array}$ \\
\hline
\end{tabular}

Figure 8. Position of M tflp mutations that affect interactions with Rpo4lp. N oninteracting $M$ tflp mutations cluster in three regions designated $A, B$, and $C$. Regions with amino acid sequence similarity to $\sigma$ factors are shaded (Jang and Jaehning 1991). 
tein therefore appears to have two distinct functions closely interdigitated in the folded structure. It is interesting that both mutations at amino acid 42 (Y 42C and $Y 42 R$ ) result in a ts phenotype in vivo (Table 1; Shadel and Clayton 1995). Because we have shown that the $Y 42 C$ mutation affects core interactions, this is probably also the defect for the $Y 42 R$ mutation. In an in vitro binding assay we can correct the defect of the $Y 42 \mathrm{C}$ mutation by lowering the $\mathrm{pH}$ to create the uncharged form of cysteine (Fig. 7). The fact that both mutations are ts in vivo may therefore reflect alterations in $\mathrm{pH}$ or ionic environment in the mitochondrion that occur at elevated temperature. Under these altered conditions, a charged residue (cysteine or arginine) at position 42 does not support interactions with the core.

We found that the temperature shift dramatically decreases mitochondrial transcription even when wildtype M tflp is present. When Mtflp is replaced by a ts noninteracting mutation (I 154T or L53H), abundance of all classes of transcripts drops rapidly at the elevated temperature and does not recover to levels that support mitochondrial function. The fact that the reduction was similar for all the promoters we examined is consistent with the idea that the subunits of the hol oenzyme could no longer interact in the altered conditions of the mitochondrion at the nonpermissive temperature.

We have not confirmed directly that RNA synthesis shuts off at the nonpermissive temperature. However, our observation that mitochondrial DNA levels do not change during the several cell generations represented by the extended time course of the experiment indicates that the decrease in transcript abundance is not attributable to a loss of template. This observation also calls into question the hypothesized role of the mIRNAP in replication of mitochondrial DNA (Clayton 1991). If, as we have shown, the mutated enzyme is nonfunctional for the synthesis of all classes of transcripts, how can it still be active for primer synthesis? This view is consistent with the work of Fangman et al. (1990), who have shown that mitochondrial DN A can be replicated in the absence of functional Rpo4lp.

\section{Comparison to the core interaction regions of $\sigma$ factors: cluster A mutations/conserved region 2}

Previous studies of the core interaction regions of bacterial $\sigma$ factors have demonstrated cl early that amino acids in conserved regions 2.1 and 2.2 are of critical importance (Shuler et al. 1995; Tintut and Gralla 1995; Joo et al. 1997). The amino acid sequences of these regions of Escherichia coli $\sigma^{70}$ and $\sigma^{32}$, and Bacillus subtilis $\sigma^{\mathrm{E}}$ are shown in Figure 9A aligned with Mtflp. Also included are a region of the human RAP30 subunit of RNA Pol II factor TFIIF shown to be protected when in a complex with the bacterial core RNA polymerase (McCracken and Greenblatt 1991), and a short region of $E$. coli $\sigma^{54}$ demonstrated to be important for core interactions ( $\mathrm{T} \mathrm{in}$ tut and Gralla 1995).

Although no point mutations of $\sigma^{70}$ have been re ported that abolish core interactions, Lesley and Burgess (1989) identified several deletions that decreased core binding. A del etion that encompassed region 2.1 had the most del eterious effect, and a synthetic pepti de spanning this region (indicated by the broken line in Fig. 9A) was found to bind to core polymerase (Lesley and Burgess 1989). However, this peptide also bound with similar
Figure 9. Alignment of the cluster A mutations with known core interaction regions of $\sigma$ and $\sigma$-like factors, and location of this region on the structure of $\sigma^{70}$. (A) Core-binding regions identified in $\sigma^{70}$ [amino acids 361-417 (Lesley and Burgess 1989)], $\sigma^{32}$ [amino acids 35-91 (Joo et al. 1997)], $\sigma^{\mathrm{E}}$ [amino acids 44-100 (Schuler et al. 1995)], Rap30 [amino acids 105-160 (McCracken and Greenblatt 1991)], Mtflp [amino acids 9-66 (this work)] and $\sigma^{54}$ [amino acids 175-193 (Tintut and Gralla 1995)] are shown. A 30-amino-acid peptide from $\sigma^{70}$ with affinity for core polymerase (Lesley and Burgess 1989) is shown by a broken line above the $\sigma^{70}$ sequence. The position of mutations that reduce interaction with core polymerase are shown in green for $\sigma^{\mathrm{E}}, \sigma^{32}$, and $\sigma^{54}$, and in red for M tflp. Colored shading is used to indicate similarity between the amino acid sequences. (B) The locations of the noninteracting mutations shown in $A$ are highlighted on the structure of region 2 of $\sigma^{70}$ as determined by Malhotra et al. (1996) using Insightll (Biosym, San Diego, CA). The Mtflp noninteracting cluster A mutations are shown in red. Positions required for interaction in $\sigma^{\mathrm{E}}, \sigma^{32}$, and $\sigma^{54}$ are shown in green. N ote that the carboxyl terminus of region 2.4 (marked with an arrow) is brought close to the position of the noninteracting mutations in regions 2.1 and 2.2 in the three-dimensional structure.

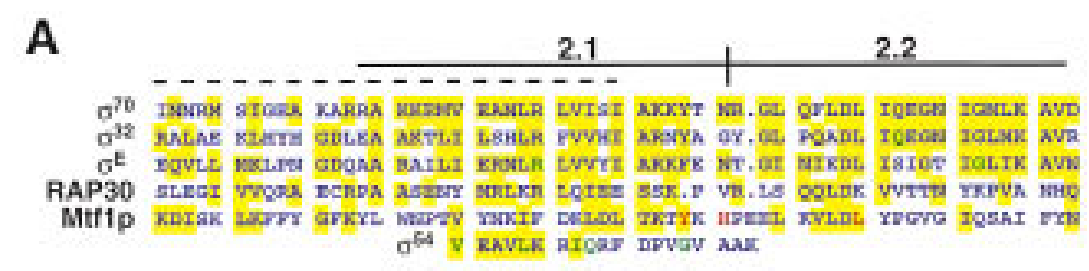

B

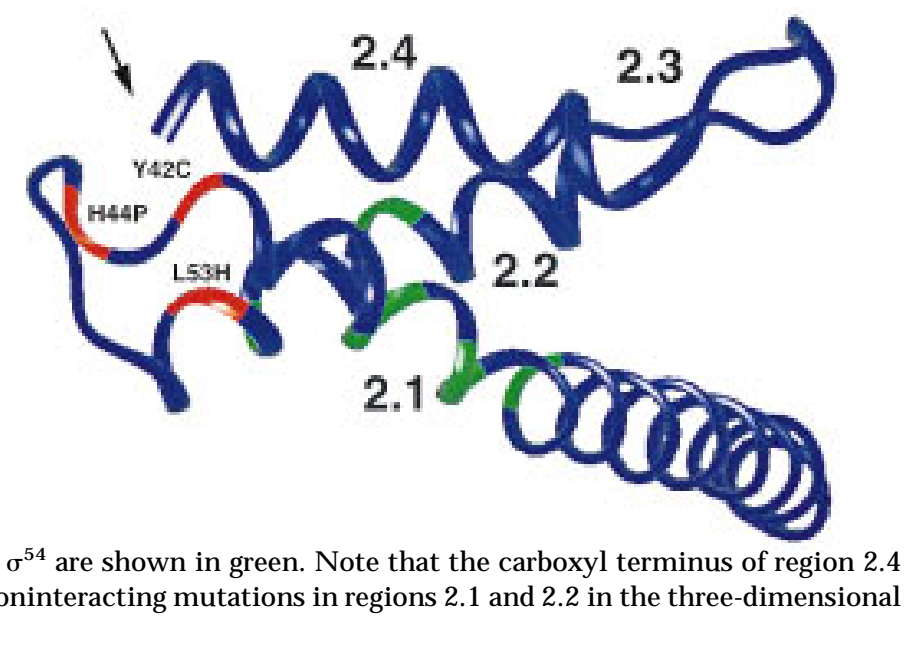


affinities to the holoenzyme form of E. coli RNA polymerase and to $\sigma^{70}$ (Lesley and Burgess 1989). Severinova et al. (1996) have extended these observations using a tryptic fragment of $\sigma^{70}$. They found that a fragment encompassing part of region 1 and most of conserved region 2 (amino acids 114-448) bound to the core polymerase. Binding by this fragment is specific, as full-length $\sigma^{70}$ was able to compete with the fragment for core binding. However, the fragment binds core with an affinity 30 fold lower than full-length $\sigma^{70}$, suggesting that other regions also make important contributions to core binding.

Recent work has focused on regions 2.1 and 2.2 of $\sigma$ factors to identify individual residues critical for core interactions. Shuler et al. (1995) screened site-directed mutations in regions 2.1 and 2.2 of $B$. subtilis $\sigma^{\mathrm{E}}$ and identified two point mutations (highlighted in Fig. 9A) that interfered with core interactions. Tintut and Gralla (1995) noted that although $\sigma^{54}$ and $\sigma^{70}$ share very little amino acid sequence similarity, a short motif can be found in both proteins. M utagenesis of this region of $\sigma^{54}$ resulted in the identification of the residues highlighted in Figure 9A as critical for core interactions (Tintut and Gralla 1995). Joo et al. (1997) found that a mutation in regi on 2.2 in $\sigma^{32}$ reduces affinity for the core pol ymerase. $\mathrm{N}$ ote that the mutations identified in these screens (shown in green) flank the highlighted mutations in cluster A of Mtflp (shown in red), and in one case, identify the same position in the alignment. Although some of the noninteracting mutations do overlap the original synthetic pepti de of Lesl ey and Burgess (1989), it is clear from this comparison that core interaction requires many amino acids in regions 2.1 and 2.2 in addition to those included in the peptide. This conclusion is consistent with predictions made by Gribskov and Burgess (1986) and Helmann and Chamberl in (1988) based on the high level of amino acid sequence conservation in these regions of the bacterial $\sigma$ factors.

The bacterial $\sigma$ factors and the eukaryotic nuclear factor RAP30 (McCracken and Greenblatt 1991) all form complexes with the bacterial core polymerase. As shown in Figure 9A, the amino acid sequence of this region of the different proteins has not been highly conserved. It is possible, however, that structural elements of the interaction region are similar. We have used the recently reported structure of a portion of $\sigma^{70}$ (M al hotra et al. 1996) to model the position of the cluster $A$ noninteracting mutations from $\mathrm{Mtflp}$ as well as the region 2.1 and 2.2 mutations of $\sigma^{32}, \sigma^{\mathrm{E}}$, and $\sigma^{54}$. As shown in Figure 9B, the highlighted positions define a structural domain including the helical region of 2.1 and a turn or bend connecting this element to helical region 2.2 .

It is of course difficult to predict the structure of these other $\sigma$-like factors accurately, especially as there are some single amino acid insertions and deletions in the region to be modeled (Fig. 9A). It is however of interest to note the location of the tyrosine residue at an accessible position near the beginning of the turn. We have shown that in Mtflp, the ionization state of this residue in the Y 42C mutation is critical for interaction. M ost $\sigma$ factors have a bulky hydrophobic residue in this position (Lon- etto et al. 1992). The fact that $\sigma^{54}$ and RAP30 do not share this residue (Fig. 9A) indicates that the determinants for binding are more complex than simple interactions between single amino acids.

\section{Cluster B mutations}

The reported structure of $\sigma^{70}$ only extends to the carboxyl terminus of region 2 (Malhotra et al. 1996), so the additional noninteracting mutations in clusters $B$ and $C$ (Fig. 8) cannot be modeled relative to the cluster A mutations in region 2 . However, as indicated by the arrow in Figure 9B, the folded structure does bring the carboxyl terminus of the region 2.4 helix into close juxtaposition with the region $2.1 / 2.2$ interaction domain. This means that the noninteracting mutations that we identified in cluster B are probably very close to those in cluster A in the folded structure. Although there is no obvious amino acid sequence similarity between this region of $\mathrm{Mtflp}$ and the $\sigma$ factors (Jang and Jaehning 1991), common structures may exist. The amino acid differences may be important for the selective interactions with different types of core polymerases. Because none of the original deletion mutations tested by Lesley and Burgess (1989) selectively removed this part of the protein between regions 2 and 3, this question has not yet been addressed.

\section{Cluster C mutations/conserved region 3}

Thethird cluster of mutations identified in our screen lie in conserved region 3. All of these mutations (S218R, $1221 \mathrm{~K}$, and D225G) are interposed very closely with petite mutations that retain the ability to interact with the core (Q219R and L228S). The spacing between these mutations indicates that they may define two important surfaces (potentially faces of a hel ical or sheet structure), one of which is critical for core interactions and the other required for another essential function. There is precedent for amino acids in region 3 also having a role in core interactions. Lesley and Burgess (1989) described one del etion that removed region 3 and reduced core interactions by a factor of 5 in vitro. In addition, Zhou et al. (1992) reported that a small deletion in $\sigma^{32}$ reduced significantly the affinity for the core polymerase. Combined with the fact that we were unable to define deletions of either Rpo4lp or Mtflp that retained the ability to interact in vivo, all of these observations strongly support a model of a complex interaction surface created by distant regions in the amino acid sequence brought together in the fol ded structure. Because our mutagenesis was not exhaustive, it is possible that even more than the three regions that we have identified are important for interactions.

\section{Interaction regions in the core polymerase}

There is currently no information on the particular residues or regions of any core polymerase requi red for factor interactions. $\sigma^{70}$ has been shown to make contacts with all of the subunits of the core $\left[\beta, \beta^{\prime}\right.$, and $\alpha$ (Coggins et al. 
1977; M cMahan and Burgess 1994; Greiner et al. 1996)]. It is probable that the eukaryotic nuclear $\sigma$-like factors also make contacts with more than one subunit of the core. The RAP30 and RAP74 subunits of TFIIF each contain core interaction regi ons in support of this idea (M CCracken and Greenblatt 1991; Wang and Burton 1995). Although the analysis of interaction elements of the single subunit Rpo4lp core should be simpler than for the multisubunit enzymes, our analysis of deletion mutations in Rpo41p (Fig. 2) support the idea that these interaction elements will encompass several widely spaced regions in the RPO 41 gene. It will be interesting to ultimately determine if these elements share any amino acid sequence or structural similarity with elements in the multisubunit prokaryotic and eukaryotic core polymerases. These studies could help to elucidate the origins of this unusual RNA polymerase.

Although there are as yet no identified homologs of the yeast MTF1 gene, it appears that most eukaryotes do possess an Rpo4lp-type mitochondrial core polymerase (Cermakian et al. 1996; Chen et al. 1996; Tiranti et al. 1997). The analysis of the interaction regions in the single polypeptide enzymes could therefore eventually expl ain the al terations that caused the phage-rel ated proteins to lose the ability to recognize a promoter on their own and to substitute a required accessory factor. The conservation of structures and functions among the RNA polymerases of phage, bacteria, and the eukaryotic nucleus and mitochondrion will allow observations of the relatively simple mitochondrial RNA polymerase to guide further experiments with the multisubunit as well as the single polypeptide enzymes.

\section{Materials and methods}

Media and genetic methods

Standard media such as YP medium containing $2 \%$ of either glucose (YPD) or glycerol (YPG), synthetic complete medium (SC) lacking the appropriate amino acids, and sporulation medium were prepared as described by Guthrie and Fink (1991). 5-FOA medium was prepared by adding 5-FOA to synthetic medium at a concentration of $500 \mathrm{mg} / \mathrm{liter}$ (Sikorski and Boeke 1991). Yeast cells were transformed using the lithium acetate method (Ito et al. 1983). Mating, sporulation, and dissection were carried out by standard methods (Guthrie and Fink 1991).

\section{Two-hybrid plasmid constructs and assays}

MTF1 was cloned as a 1.0-kb EcoRI fragment from pJJ525 (M angus et al. 1994) into the corresponding site of pBT M 116 (Bartel et al. 1993) to create plasmid pJj832. Insert orientation was confirmed by restriction enzyme analysis. For mutant mtf1 constructions, pJJ832 was digested with $\mathrm{Nsil}$ and religated to produce an internal deletion of $101 \mathrm{bp}$. The resulting plasmid was digested with either AfIII and $\mathrm{Mscl}$ or AflII and Pstl. The fragments were treated with shrimp alkaline phosphatase. mtf1 mutations created by site-directed mutagenesis in pBluescript SK $(+)$ were digested with AfIII and Pstl (vector sequence) and ligated to pJJ832. mtf1 mutants isolated as single point mutations (I221K, L53H, I154T, and S218R) were digested with AfIII and $\mathrm{MsCl}$, and ligated to the corresponding digest of pJJ832. Resulting plasmids were tested by restriction analysis to confirm the replacement of the mtf1 deletion with the point mutation constructs. Mutants $\mathrm{Y} 42 \mathrm{C}$ and K157E were first cloned into pBluescript SK $(+)$, then the AflII to Pstl fragments were cloned into pJj832.

\section{Two-hybrid deletion constructs}

For carboxy-terminal deletions, plasmid pBT M 116 was digested with EcoRI and Smal. The vector was dephosphorylated with shrimp alkal ine phosphatase (U.S. Biochemical), then separated by electrophoresis on an agarose gel and extracted from the gel using Qiaex beads (Qiagen). The vector was ligated to the following MTF1 fragments of pJJ525. For the Mtf1pl-224 construct, the EcoRI to BamHI fragment of MTF1 from pJJ525 was used as the insert. The EcoRI to Bglll fragment of this same vector was used for the Mtf1pl-296 construct. And finally, the EcoRI to Xmnl fragment was used to clone the Mtflp1-315 construct. Inserts were prepared as follows. pJJ525 was digested with either BamHI, BglII, or Xmnl. Blunt ends were then created by filling in the overhang with Klenow ( $\mathrm{N}$ ew England Biolabs) followed by digestion with EcoRI. Fragments were separated by electrophoresis through $0.8 \%$ agarose gels and purified using Qiaex beads (Qiagen). For the amino-terminal deletion (M tf1p52-341) a Scal to Pstl (partial Scal digest) fragment from pJJ525 was inserted into the Smal and Pstl sites of pBTM 116. Vector and insert were prepared as described above.

Rpo4lp two-hybrid constructs were prepared using RPO 41 fragments generated from the following PCR primers. Restriction sites in the primers are underscored: NOTI-5', 5'-CAGGCCTGCGCGGCCGCAGATGCTGAGACCGGCCTATAAATC-3'; NOTI-3', 5'-GCGGATCCGGGCGGCCGCGAAAAAATATTGACTGTTTCTCAATAC-3'; 5'-318, 5'-GCCGCCGCGGATCCACGGTTCAACAGAAGTCTTG-3'; BAM-HI-5', 5'-CGCGGGATCCTGATGCTGAGACCGGCCTATAAATCGC-3'; 3'-311, 5'-CGAAGAGGATCCAAGGAAGG-3'; 3'-597, 5'-GCGCGGATCCTAATACTCTGAGGC-3'.

The PCR fragments were cloned into TA cloning vectors (pGEMT, Promega; pCRII, Invitrogen) and then digested with the appropriate enzymes for cloning. Insert fragments as well as vector fragments were separated by el ectrophoresis and purified as described above. The Rpo41p1-1351 insert was prepared by the amplification of an RPO41 plasmid using the NOTI-5' and NOTI-3' primers. The insert was created by a Notl digest and cloned into the corresponding site of pVP16 (Hollenberg et al . 1995). The Rpo41p1-311 insert was prepared using the BAM HI$5^{\prime}$ and $3^{\prime}-311$ primers. The insert was created by a BamHI digestion and ligated into the BamHI site of pVP16. Primers 5'318 and NOTI-3' were used to amplify the Rpo41p318-1351 insert. The insert was cloned into the BamHI and Notl sites of pVP16 after digestion with the same enzymes. The Rpo41p1918 insert was created by digesting the Rpo41p1-1351 clone with $\mathrm{N}$ otl and $\mathrm{Mscl}$. The fragment was ligated to pVP16 that had been digested with EcoRI, filled in with Klenow to make blunt ends, then digested with $\mathrm{N}$ otl. The Rpo41p318-597 insert was created with the $5^{\prime}-318$ and $3^{\prime}-597$ primers. The insert was cloned into the BamHI site of pVP16. The Rpo41p1-597 fragment was amplified with the BAM HI-5' and 3'-597 primers. The insert was created by partial digestion with BamHI (there is a BamHI site in the Rpo4lp sequence) and ligated to the corresponding site of pVP16. T wo-hybrid constructs containing LexA and VP16 fusions were transformed into yeast strains AMR70 and L40, respectively (Hollenberg et al. 1995). To test the constructs for interactions, the hapl oid strains were mated and diploids were selected on Ura-, Trp-, Leu-medium. The strains were tested initially for $\beta$-gal actosi dase production by filter lift assays (Breeden and Nasmyth 1985), and for growth on plates 
lacking histidine and containing $5 \mathrm{~mm}$ 3-aminotriazole (Phizicky and Fields 1995). For quantitative assays, strains were grown to mid-log phase in selective medium and $\beta$-galactosidase activity was assayed in permeabilized cells (M iller 1972).

Plasmid and strain construction for the MTF1 plasmid shuffle

Plasmids pJ $\mathrm{H} 118, \mathrm{pJH} 121$, and $\mathrm{pJ} \mathrm{H} 124$ were constructed by inserting a 1.5-kb EcoRI fragment containing the promoter and entire coding sequence of MTF1 (M angus et al. 1994) into the EcoRI site of pU C18, pU C 7, and pBLUESCRIPT SK(+). Plasmids $\mathrm{pJ} \mathrm{H} 119$ and $\mathrm{pJ} \mathrm{H} 142$ were made by cloning this EcoRI fragment into the U RA $3^{+}$vector Y C plac33, and LEU $2^{+}$vector Y C plac111 (Gietz and Sugino 1988), respectively. To construct plasmid pJ H133, a 3.8-kb BgllI-BamHI fragment bearing a 3.8-kb hisGU RA3-hisG cassette was isolated from plasmid pN KY 51 (Alani et al. 1987), and was inserted into the Bglll site of plasmid pJ $\mathrm{H} 121$, disrupting the MTF1-coding sequence.

The isogenic diploid yJ H60 was made by crossing yJ H58 (M ATa his4 309 ura3-52 inol-13 leu2-3,112) and yJH59 (MAT $\alpha$ his4 309 ura3-52 ino1-13 leu2-3,112). The heterozygous MTF1/ mtf1::hisG-URA3-hisG strain yJH61 was made from yJH60 by one step gene replacement (Rothstein 1983) of the 5.3-kb EcoRI fragment from pJ H133. Strain yJ H64 was made by selecting for loss of the URA3 gene from the heterozygous MTF1/mtf1 yJ 61 on 5-FOA medium. To construct recipient strain yJ H71, strain yJ 64 was transformed with $\mathrm{pJ} H 119$ containing a functional MTF1 gene and the resulting transformants were sporulated to generate mtf1:hisG (pJH119) haploid progeny whose genotype was tested on both YPG and 5-FOA media. All strain constructions were confirmed using a 1-kb EcoRI fragment of pJH117 (pJJ517) as an MTF1 probe.

\section{PCR-based mutagenesis and isolation of mtf1 mutants}

Mutagenic PCR was performed essentially as described previously (Leung et al. 1989) to generate in vitro random mutations of MTF1. Plasmid pJH 118 containing a 1.5-kb EcoRI fragment of MTF1 was used as a DNA template. A 17-mer of universal sequencing primer and a 23-mer oligonucleotide, 5'-CACAGGAAACAGCTATGACCATG-3', encompassing the reverse sequencing primer were used as primers. The PCR reactions contained $30 \mathrm{~mm}$ Tricine at $\mathrm{pH} 8.4,10 \mathrm{ng}$ of $\mathrm{pJH} 118,0.2 \mathrm{~mm}$ dNTPs, $7 \mathrm{~mm} \mathrm{M} \mathrm{gCl} 2,0.5 \mathrm{~mm} \mathrm{M} \mathrm{nCl}_{2}, 20$ pmoles of each primer, $5 \mathrm{~mm}$ $\beta$-mercaptoethanol, $0.01 \%$ gelatin, 1 unit of Taq polymerase (the gift of N . Pace, Indiana U niversity). Reactions were done in $100 \mu \mathrm{l}$ and preheated to $92^{\circ} \mathrm{C}$ for an initial denaturation step followed by 30 cycles. The PCR-amplified fragment was purified by electrophoresis on a $0.7 \%$ agarose gel and used for the introduction of mutations into yeast with the plasmid pJ $\mathrm{H} 142$ gapped with BamHI. The gap-dupl ex recombinant mutagenesis was performed as described by Muhlrad et al. (1992). Y east strain yJ H 71 was transformed to $\mathrm{Leu}^{+}$with $500 \mathrm{ng}$ of PCR-amplified fragment and $100 \mathrm{ng}$ of gapped pJ H142. Approximately 10,000 individual $\mathrm{Leu}^{+}$transformants were plated on 5-FOA plates to sel ect those that lost $\mathrm{pJ} H 119$ containing the functional MTF1 gene. 5-FOA resistant $\mathrm{Leu}^{+}$transformants were screened for loss of mitochondrial function caused by $\mathrm{mtfl}$ mutations in plasmid pJ $\mathrm{H} 142$ by plating them on both YPD and YPG media. The replica plates were subsequently incubated at $30^{\circ} \mathrm{C}$ and $37^{\circ} \mathrm{C}$ for 3-6 days. Strains that did not grow on YPG medium at $30^{\circ} \mathrm{C}$ were isolated as mtf1 mutants, and those that grew on YPG medium at $30^{\circ} \mathrm{C}$ but not $37^{\circ} \mathrm{C}$ were also isolated and retested for the conditional phenotype. Mutated plasmids were recovered, passaged through $\mathrm{E}$. coli, and sequenced by the
Sanger dideoxy method (Sanger et al. 1977). To ensure that the mtf1 mutant alleles were responsible for the observed phenotypes, the recovered plasmids were transformed into yJ $\mathrm{H} 71$ followed by 5-FOA selection. When the recovered alleles contained multiple point mutations, oligonucleotide-directed mutagenesis reactions were performed to isol ate the corresponding single point mutations. The mutagenic oligonucleotides were designed so that each alteration in coding sequence was accompanied by a silent mutation altering a restriction site: H44P, 5'-ATAAACCTCCAGAAGAATTGAAGGTACT-3', delete Scal; V135A, 5'-TTTCTAACAGCTGCTAATGT-3', add Pvull; L228S, 5'-ATGGGACCCCATTTCATTTAG-3', delete BamHI; S81N 5'-GAAAAACGATCGAATCTCTACAA-3', add Pvul; E114V, 5'-ATCTAATCGATGTAGAGCGA-3', add Clal; Y54F, 5'-GAAAGTGCTTGACCTCTTCCCTGG-3', delete Scal; D225G, 5'-AAGAATGGGGTCCCATTTT-3', delete BamHI; C192F, 5'-CTAGATCTAAATTTTCAGTA-3', add Bglll; Q219R, 5'GATAGTCGATGTATAGAAG-3', del ete N sil; R79H, 5' -AGAAAAACACTCGAGTCTCT-3', add Xhol; D2.1, 5'-CAATAAAATCTTTAAACATCCAGAAGAA-3', delete 34-42, add Dral; D2.2, 5'-CCAGAAGAATTGAAGATCTTTTATAATAAA3', delete 50-62, add BgllI.

Uracil-containing single-stranded DNA was produced from plasmid pJ 124 in E. coli strain CJ236 [dut ung (Kunkel et al. 1987)]. Each mutagenic oligonucleotide was phosphorylated with T4 polynucleotide kinase and used separately in in vitro mutagenesis reactions. The resulting mutated DN As were used to transform E. coli strain N M 522 [dut ung (Kunkel et al. 1987)] to select for the mutated plasmids. Each mtf1 mutation was confirmed by sequencing and subcloned into the EcoRI site of YCplac111 to give individual constructs and retested in $\mathrm{yJH} 71$ as noted above.

\section{RNA isolation and analysis}

Yeast were grown to mid-log phase, collected by centrifugation and frozen as pellets in liquid nitrogen. Yeast total RNA was isolated and purified as described by Elder et al. (1983). Yeast total RN A (10-20 $\mu \mathrm{g})$ was el ectrophoresed through agarose gels containing formaldehyde and blotted by capillary action to Zetaprobe nylon membranes (BioRad). Oligonucleotide probes specific for mitochondrial 14S, COB, and tRN A ${ }^{\text {Thr }}$ and cytoplasmic 18S RNAs (Ulery et al. 1994) were end-labeled with [ $\gamma$ ${ }^{32} \mathrm{PJATP}$ (Amersham) and hybridized at $40^{\circ} \mathrm{C}$ in $0.5 \mathrm{~m}$ sodium phosphate buffer (pH 7.5) and 7\% SDS. An oligonucleotide specific for $18 \mathrm{~S}$ rRN A was used to normalize for differences in RN A samples on the blot. Signal intensity was quantitated with a Phosphorlmager (M olecular Dynamics).

\section{Western blots}

Yeast cell extracts were prepared by growing cells to an $\mathrm{OD}_{595}$ of 0.6. Cells $(10 \mathrm{ml})$ were harvested and resuspended in $1 \mathrm{ml}$ of ice-cold Z buffer $\left(60 \mathrm{~mm} \mathrm{Na}_{2} \mathrm{HPO}_{4}, 40 \mathrm{~mm} \mathrm{NaHPO}, 10 \mathrm{~mm}\right.$ $\mathrm{KCl}, 1 \mathrm{mM} \mathrm{MgSO}_{4}$, and $50 \mathrm{mM} \beta$-mercaptoethanol at pH 7.0). Cells were pelleted in a microfuge and resuspended in $200 \mu \mathrm{l}$ of ice-cold $Z$ buffer. Glass beads ( $300 \mu \mathrm{l})$ were added and the cells were vortexed for $5 \mathrm{~min}$ at $4^{\circ} \mathrm{C}$. The extract was cleared by a 5-min centrifugation (maximum speed) and the supernatant was collected. Protein concentrations were determined by the Bradford method (Bradford 1976) using BSA as a standard. Total protein $(50-100 \mu \mathrm{g})$ were separated by SDS-PAGE and blotted to Immobilon-P (Millipore). Rpo4lp was detected by polyclonal antibodies as described previously ( $M$ angus et al. 1994). Twohybrid Mtflp constructs were detected using anti-LexA antibody generously provided by Dr. Roger Brent (Harvard Univer- 
sity, Cambridge, MA). Hybridization conditions were as de scribed by Harlow and Lane (1988). Detection was by chemiluminescence using ECL kits from Amersham Corp.

\section{GST-fusion plasmid constructs and GST-Mtflp} affinity chromatography

The internal AflII-Bglll fragment from the mtf1 mutants was used to replace the wild-type sequence of MTF1 in pGEX-1 [plasmid pJJ526 (M angus et al. 1994)]. pJJ526 was digested with N sil and religated to produce a deletion of $101 \mathrm{bp}$. The resulting plasmid was digested with AflII and Bglll followed by dephosphorylation of ends by shrimp alkaline phosphatase (U.S. Biochemical). The vector was isolated by gel electrophoresis and ligated to AflII-BglII fragments from the MTF1 mutants. The resulting plasmids were tested by restriction enzyme analysis to confirm insertion of the full-length mutant fragments. Interaction studies with GST-M tf1p constructs were performed as described previously (Mangus et al. 1994) with the following adjustments. Proteins were el uted with a 5-column volume step of $\mathrm{T}(500)$ buffer. The $\mathrm{pH}$ of the $\mathrm{T}(50)$ and $\mathrm{T}(500)$ solutions was 7.9 at $25^{\circ} \mathrm{C}$ and 8.3 at $4^{\circ} \mathrm{C}$. When chromatography was performed at $\mathrm{pH}$ 7.3, MOPS buffer was used instead of Tris- $\mathrm{HCl}$ in the solutions.

\section{Acknowledgments}

We thank Margaret Short and Anne Whalen for help with the two-hybrid constructs, Roger Brent for anti-LexA antibody, Mike Woontner for thoughtful discussions and comments on the manuscript, Tom Blumenthal for comments on the manuscript, Seth Darst for the $\sigma^{70}$ coordinates, and Paul Hagerman and Elsi Vacano for help with computer modeling. This work was supported by grants from the $\mathrm{N}$ ational Institutes of Heal th (GM 36692 awarded to J.A.J., and P30 CA46934 to the University of Colorado Cancer Center DN A Sequencing Core Facility); S.-H.J. was supported by a grant from the Genetic Engineering Research Fund (1995) of the Korean Ministry of Education.

The publication costs of this article were defrayed in part by payment of page charges. This article must therefore be hereby marked "advertisement" in accordance with 18 USC section 1734 solely to indicate this fact.

\section{References}

Alani, E., L. Cao, and N. Kleckner. 1987. A method for gene disruption that al lows repeated use of U RA 3 sel ection in the construction of multiply disrupted yeast strain. Genetics 116: $541-545$.

Bartel, P.L., C. Chien, R. Sternglanz, and S. Fields. 1993. Using the two-hybrid system to detect protein-protein interactions. In Cellular interactions in development: A practical approach (ed. D.A. Hartley), pp. 153-179. IRL Press, Oxford, UK.

Bradford, M .M. 1976. A rapid and sensitive method for the quantitation of microgram quantities of protein utilizing the principle of protein-dye binding. Analyt. Biochem. 72: 248-254.

Breeden, L. and K. N asmyth. 1985. Regulation of the yeast HO gene. Cold Spring Harb. Symp. Q uant. Biol. 50: 643-650.

Cermakian, N., T.M. Ikeda, R. Cedergren, and M.W. Gray. 1996. Sequences homologous to yeast mitochondrial and bacteriophage T3 and T 7 RN A polymerases are widespread throughout the eukaryotic lineage. Nucleic Acids Res. 24: 648-654.

Chen, B., A.R. Kubelik, S. Mohr, and C.A. Breitenberger. 1996. Cloning and characterization of the Neurospora crassa cyt-5 gene. J. Biol. Chem. 271: 6537-6544.
Coggins, J.R., J. Lumsden, and A.D. Malcom. 1977. A study of the quaternary structure of E. coli RNA polymerase using bis(imido esters). Biochemistry 16:1111-1116.

Conaway, R.C. and J.W. Conaway. 1993. General initiation factors for RNA polymerase II. Annu. Rev. Biochem. 62: 161190.

Clayton, D.A. 1991. Nuclear gadgets in mitochondrial DNA replication and transcription. Trends Biol. Sci. 16:107-111.

Delarue, M., O. Poch, N. Tordo, D. Moras, and P. Argos. 1990. An attempt to unify the structure of polymerases. Protein Eng. 6: 461-467.

Dieckmann, C.L. and R.R. Staples. 1994. Regulation of mitochondrial gene expression in Saccharomyces cerevisiae. Int. Rev. Cytology 152: 145-181.

Dombroski, A., W. Walter, and C. Gross. 1993. Amino-terminal amino acids modulate $\sigma$-factor DN A-binding activity. Genes \& Dev. 7: 2446-2455.

Elder, R.T., E.Y. Loh, and R.W. Davis. 1983. RN A from the yeast transposable element Tyl has both ends in the direct repeats, a structure similar to retrovirus RNA. Proc. Natl. Acad. Sci. 80: 2432-2436.

Fangman, W.L., J.W. Henly, and B.J. Brewer. 1990. RPO41-Independent maintenance of (rho $\rightarrow$ mitochondrial DNA in Saccharomyces cerevisiae. Mol. Cell. Biol. 10: 10-15.

Gietz, R.D. and A. Sugino. 1988. New yeast-Escherichia coli shuttle vectors constructed with in vitro mutagenized yeast genes lacking six-base pair restriction sites. Gene 74: 527534.

Greiner, D.P., K.A. Hughes, A.H. Gunasekera, and C.F. M eares. 1996. Binding of the sigma 70 protein to the core subunits of E. coli RN A polymerase, studied by iron-EDTA protein footprinting. Proc. Natl. Acad. Sci. 93: 71-75.

Gribskov, M. and R.R. Burgess. 1986. Sigma factors from E. coli, B. subtilis, phage SP01, and T4 are homologous proteins. Nucleic Acids Res. 14: 6745-6763.

Guthrie, C. and G.R. Fink. 1991. Guide to yeast genetics and molecular biology. Methods Enzymol. 194: 1-37.

Harlow, E. and D. Lane. 1988. Antibodies: A laboratory manual. Cold Spring Harbor Laboratory Press, Cold Spring Harbor, NY.

Helmann, J.D. 1994. Bacterial sigma factors. in Transcription: Mechanisms and regulation (ed. R.C. Conaway and J.W. Conaway), pp. 1-17. Raven Press, N ew York, NY.

Helmann, J.D. and M.J. Chamberlin. 1988. Structure and function of bacterial sigma factors. Annu. Rev. Biochem. 57: 839-872.

Hollenberg, S.M., R. Sternglanz, P.F. Cheng, and H. Weintraub. 1995. Identification of a new family of tissue-specific basic helix-loop-helix proteins with a two-hybrid system. Mol. Cell. Biol. 15: 3813-3822.

Ito, H., Y. Fukuda, K. Murata, and A. Kimura. 1983. Transformation of intact yeast cells treated with alkalai cations. J. Bacteriol. 153: 163-168.

Jaehning, J.A. 1993. Mitochondrial transcription: Is a pattern emerging? Mol. Microbiol. 8: 1-4.

Jang, S.H. and J.A. Jaehning. 1991. The yeast mitochondrial RN A polymerase specificity factor, MTF1, is similar to bacterial sigma factors. J. Biol. Chem. 266: 22671-22677.

- - 1994. Mechanisms of mitochondrial transcription. in Transcription: Mechanisms and regulation (ed. R.C. Conaway and J.W. Conaway), pp. 171-184. Raven Press, New York, NY.

Joo, D.M., N. N g, and R. Calendar. 1997. A $\sigma^{32}$ mutant with a single amino acid change in the highly conserved region 2.2 exhibits reduced core RN A polymerase affinity. Proc. Natl. Acad. Sci. 94: 4907-4912. 
Kunkel, T.A., J.D. Roberts, and R.A. Zakour. 1987. Rapid and efficient site-specific mutagenesis without phenotypic selection. Methods Enzymol. 154: 367-382.

Lesley, S.A. and R.R. Burgess. 1989. Characterization of the Escherichia coli transcription factor sigma 70: Localization of a region involved in the interaction with core RNA polymerase. Biochemistry 28: 7728-7734.

Leung, D.W., E. Chen, and D.V. Goeddel. 1989. A method for random mutagenesis of a defined DNA segment using a modified polymerase chain reaction. Technique 1: 11-15.

Lisowsky, T. and G. Michaelis. 1988. A nuclear gene essential for mitochondrial replication suppresses a defect of mitochondrial transcription in Saccharomyces cerevisiae. Mol. \& Gen. Genet. 214: 218-223.

Lonetto, M., M. Gribskov, and C.A. Gross. 1992. The sigma 70 family: Conservation and evolutionary relationships. J. Bacteriol. 174: 3843-3849.

Malhotra, A., E. Severinova, and S.A. Darst. 1996. Crystal structure of a sigma 70 fragment from E. coli RNA polymerase. Cell 87: 127-136.

M angus, D.A., S.-H. Jang, and J.A. Jaehning. 1994. Release of the yeast mitochondrial RN A polymerase specificity factor from transcription complexes. J. Biol. Chem. 269: 26568-26574.

Masters, B.S., L.L. Stohl, and D.A. Clayton. 1987. Yeast mitochondrial RNA polymerase is homologous to those encoded by bacteriophages T3 and T7. Cell 51: 89-99.

McCracken, S. and J. Greenblatt. 1991. Related RN A polymerase-binding regions in human Rap30/74 and Escherichia coli sigma 70. Science 253: 900-902.

McM ahan, S.A. and R.R. Burgess. 1994. Use of aryl azide crosslinkers to investigate protein-protein interactions: An optimization of important conditions as applied to E. coli RNA polymerase and localization of a sigma 70 -al pha cross-link to the C-terminal region of alpha. Biochemistry 33: 12092-12099.

Miller, J.H. 1972. Experiments in molecular genetics. Cold Spring Harbor Laboratory Press, Cold Spring Harbor, NY.

M uhl rad, D., R. Hunter, and R. Parker. 1992. A rapid method for localized mutagenesis of yeast genes. Yeast 8: 79-82.

Osinga, K.A., M.D. Haan, T. Christianson, and H.F. Tabak. 1982. A nonanucleotide sequence involved in promotion of ribosomal RNA synthesis and RNA priming of DNA replication in yeast mitochondria. Nucleic Acids Res. 10: 79938006.

Phizicky, E.M . and S. Fields. 1995. Protein-protein interactions: Methods for detection and analysis. Microbiol. Rev. 59: 94123.

Polyakov, A., E. Severinova, and S.A. Darst. 1995. Three-Dimensional structure of E. coli core RNA polymerase: Promoter binding and el ongation conformations of the enzyme. Cell 83: 365-373.

Rothstein, R.J. 1983. One step gene disruption in yeast. Methods Enzymol. 101: 202-211.

Sanger, F., S. Nicklen, and A.R. Coulson. 1977. DN A sequencing with chain-terminating inhibitors. Proc. Natl. Acad. Sci. 12: 5463-5467.

Severinova, E., K. Severinova, D. Fenyo, M. Marr, E.N. Brody, J.W. Roberts, B.T. Chait, and S.A. Darst. 1996. Domain organization of the Escherichia coli RN A polymerase sigma 70 subunit. J. Mol. Biol. 263: 637-647.

Shadel, G.S. and D.A. Clayton. 1995. A Saccharomyces cerevisiae mitochondrial transcription factor sc-mtTFB, shares features with sigma factors but is functionally distinct. Mol. Cell. Biol. 15: 2101-2108.

Shuler, M.F., K.M. Tatti, K.H. Wade, and C.P. M oran Jr. 1995. A single amino acid substitution in sigma $E$ affects its ability to bind core RN A polymerase. J. Bacteriol. 177: 3687-3694.

Sikorski, R.S. and J.D. Boeke. 1991. In vitro mutagenesis and plasmid shuffling: From cloned gene to mutant yeast. Methods Enzymol. 194: 302-318.

Sousa, R., Y. Chung, J. Rose, and B. Wang. 1993. Crystal structure of bacteriophage T7 RNA polymerase at $3.3 \AA$ resolution. Nature 364: 593-599.

Tintut, Y. and J.D. Gralla. 1995. PCR mutagenesis identifies a polymerase-binding sequence of sigma 54 that includes a sigma 70 homology region. J. Bacteriol. 177: 5818-5825.

Tiranti, V., A. Savoia, F. Forti, M.-F. D'A polito, M. Centra, M. Rocchi, and M. Zeviani. 1997. Identification of the gene encoding the human mitochondrial RNA polymerase ( $h$ $\mathrm{mtRPOL}$ ) by cyberscreening of the expressed sequence tags database. Hum. Mol. Genet. 6: 615-625.

Ulery, T.L., S.-H. Jang, and J.A. Jaehning. 1994. Glucose repression of yeast mitochondrial transcription: Kinetics of dere pression and role of nuclear genes. Mol. Cell. Biol. 14: 11601170.

Walsh, C. 1979. Enzymatic reaction mechanisms. W.H. Freeman and Co., San Francisco, CA.

Wang, B.Q. and Z.F. Burton. 1995. Functional domains of human RAP74 including a masked polymerase binding domain. J. Biol. Chem. 270: 27035-27044.

Zawel, L., K.P. Kumar, and D. Reinberg. 1995. Recycling of the general transcription factors during RN A polymerase II transcription. Genes \& Dev. 9:1479-1490.

Zhou, Y.N., W.A. Walter, and C.A. Gross. 1992. A mutant sigma 32 with a small deletion in conserved region 3 of sigma has reduced affinity for core RN A polymerase. J. Bacteriol. 174: 5005-5012. 


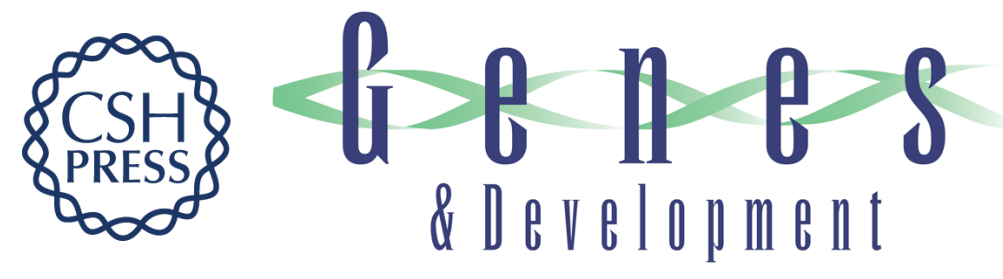

\section{Identification of three regions essential for interaction between a $\varsigma$-like factor and core RNA polymerase}

Paul F. Cliften, Jae-Young Park, Brian P. Davis, et al.

Genes Dev. 1997, 11:

Access the most recent version at doi:10.1101/gad.11.21.2897

References

This article cites 46 articles, 22 of which can be accessed free at: http://genesdev.cshlp.org/content/11/21/2897.full.html\#ref-list-1

\section{License}

Email Alerting

Receive free email alerts when new articles cite this article - sign up in the box at the top Service right corner of the article or click here.

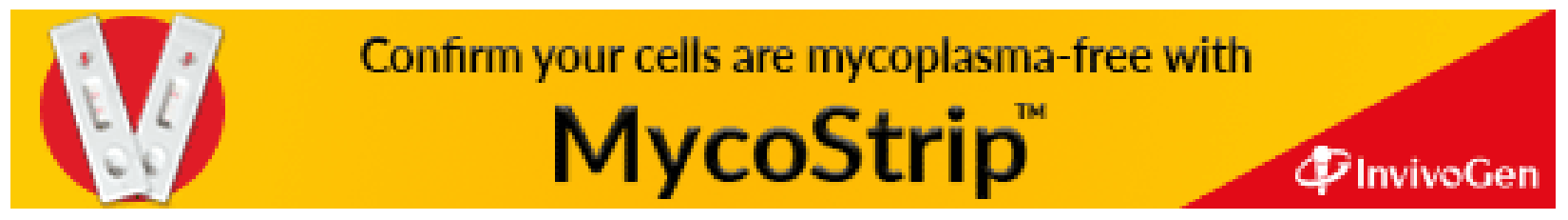

